\title{
Investigation on composite polymer and silica fume- rubber aggregate pervious concrete
}

\author{
Ali Toghroli, Mahdi Shariati, Mohamed Rehan Bin Karim and Zainah Ibrahim
}

\begin{abstract}
Many researchers are trying to obtain a pervious concrete with better physical and mechanical properties to be used in pavement. To achieve the optimized pervious concrete, different researchers have been using different materials, especially those waste materials which are existing worldwide, specifically in the compactly populated areas. Discarded tires are among them and rubber tire particles are being currently used to be considered as recycled waste materials. In this paper a combination of polymer, silica fume and rubber aggregate from rubber tire particles were used to obtain an optimized pervious concrete. The produced concrete's properties were studied. The results indicate that this pervious concrete with the optimum replacing ratio of silica fume, polymer and rubber aggregate to mineral aggregate has higher flexural and compressive strength. The relative flexural and compressive strength of this pervious concrete has been increased $31 \%$ and $18 \%$ compared to the mineral aggregate pervious concrete. The most properties of this pervious concrete are enhanced. The impact resistance of this pervious concrete is improved $8 \%$ compared to mineral aggregate pervious concrete and the permeability meet the standard of Open-Graded Fraction Course. This pervious concrete significantly reduces the elasticity modulus of usual pervious concrete. The impact resistances improved remarkably
\end{abstract}

Keywords - Polymer, Silica fume, Rubber, Pervious concrete, Porosity, Permeability, Strengths, Stress-strain, Abrasion resistance, Impact resistance

\section{Introduction}

Pervious concrete is a sustainable pavement with high permeability. To achieve the optimized pervious concrete, different researchers have been using different materials [1].

Ali Toghroli

University of Malaya

Malaysia

Mahdi Shariati

University of Malaya

Malaysia

Mohamed Rehan Bin Karim

University of Malaya

Malaysia

Zainah Ibrahim

University of Malaya,

Malaysia
In this paper a combination of polymer, silica fume and rubber aggregate were used to obtain an optimized pervious concrete.

Concrete containing silica fume can have very high strength durable. Silica fume is known to improve both the mechanical properties and durability of concrete [2, 3].

Innovative solutions to meet the challenge of tire disposal have long been in development, the promising options are: use of tire rubber in asphaltic or cement concrete mixtures [4, 5]. The use of waste tires as concrete aggregate is a possible and economical disposal solution [6]. Waste rubber tire as fine aggregates can be an economical and sustainable alternative to river sand. Few studies have attempted to utilize waste rubber tire as partial replacement of fine aggregate in the form of rubber ash [1, 3, 5, 7-10].

As a previous material, polymer pervious cement concrete can reduce traffic noise and increase drainage property of the pavement [11].

In this paper, the scrap tire rubber aggregate is used to substitute the mineral aggregate of the polymer pervious concrete to improve the flexibility and ductility. Then to achieve higher strengths of the concrete, silica fume [3] was added, hence a new type of polymer-rubber aggregate pervious concrete is prepared. The mechanical properties of this concrete are investigated.

\section{Experimental materials and methods}

\section{A. Materials}

A series of aggregate with different size were used in this paper, their particle distribution curves are shown in "Fig. 1". Two types of rubber aggregate size means type A and B have been used. The size of A rubber aggregate varies from 1.18 to $4.75 \mathrm{~mm}$ and the size of B rubber aggregate varies from 0.6 to $2.36 \mathrm{~mm}$. The density of the rubber aggregate used in this work is $1.02 \mathrm{~g} / \mathrm{cm} 3$. The particle size distribution of the rubber aggregates is presented in "Fig. 2".

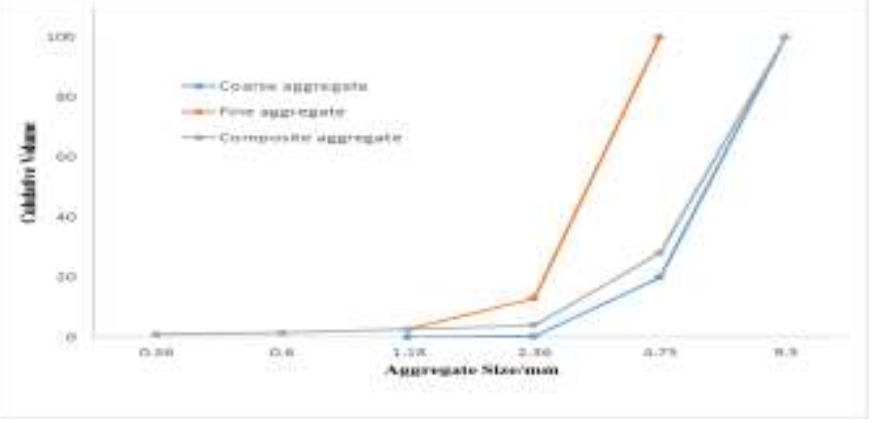

Figure 1. Particle size distribution of rubber aggregate. 


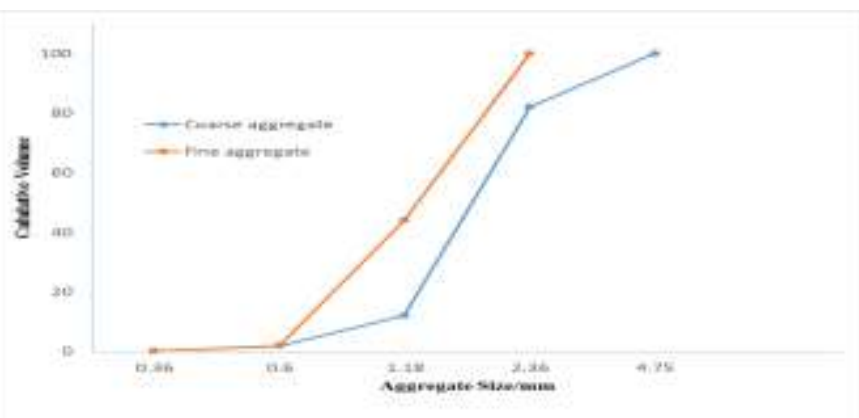

Figure 2. Particle size distribution of rubber aggregate

The cement used in this investigation was ordinary Portland cement. The physical properties of the cement are shown in "Table 1".

Table 1 . The physical performances of the cement

\begin{tabular}{ll}
\hline Physical properties & Portland cement \\
\hline Apparent density $(\mathrm{g} / \mathrm{cm} 3)$ & 3.14 \\
Specific surface $(\mathrm{m} 2 / \mathrm{kg})$ & 345 \\
Water requirement of normal consistence $(\%)$ & 27.2 \\
Setting time (min) & \\
Initial & 130 \\
Final & 195 \\
Flexural strength $(\mathrm{MPa})$ & \\
3d & 6.9 \\
28d & 9.4 \\
Compressive strength $(\mathrm{MPa})$ & \\
3d & 27.4 \\
28d & 52.6 \\
Soundness & Qualified \\
\hline
\end{tabular}

A type of styrene-butadiene latex (milky fluid) with commercial name SD623. Its physical properties are shown in "Table 2".

Table 2. The physical properties of the polymer styrofoam d623 latex

\begin{tabular}{ll}
\hline Physical properties & Value \\
\hline Solid content (\%) & 50 \\
Viscosity (mPa s) & 40 \\
Surface tension (mN/m) & 31 \\
Vitrification point (LC) & 11 \\
\hline Chemical and physical characteristics of silica fume is shown \\
in "Table 3". \\
Table 3. The physical properties of the silica fume \\
\hline Physical properties & \\
\hline SiO2 $(\%)$ & Value \\
Al2O3 $(\%)$ & 90.90 \\
Fe2O3 $(\%)$ & 1.12 \\
CaO $(\%)$ & 0.69 \\
SO3 $(\%)$ & 0.38 \\
Specific surface $\left(\mathrm{m}^{2} / \mathrm{g}\right)$ & 18 \\
Density $\left(\mathrm{kg} / \mathrm{m}^{3}\right)$ & 2260 \\
\hline
\end{tabular}

\section{B. Concrete mix proportion}

Concrete mix proportions are listed in "Table 4". Different types of mix proportion has been defined means CSP, ASP and BASP. CSP is polymer and silica fume pervious concrete without adding any rubber aggregates; ASP is polymer and silica fume pervious concrete which various volume of its coarse aggregates are replaced by A rubber aggregates; BASP is polymer and silica fume pervious concrete which various volume of its fine aggregates is replaced by $\mathrm{B}$ rubber aggregates. The replacing value of $\mathrm{A}$ rubber aggregate in BASP is the optimum ratio i.e. $18 \%$ [1]. There are seven replacement values varying from $0 \%$ to $30 \%$, i.e. $0 \%, 6 \%$, $10 \%, 14 \%, 18 \%, 22 \%, 26 \%$ and $30 \%$ in both testing serials of ASP and BASP [1]. The finer rubber aggregate is used to replace the mineral aggregate to avoid segregation and happened to get matrix with similar void ratio as the matrix without rubber aggregate. The solid polymer in this material is $19 \%$ (the latex is 18\%) of the mass of cement and the silica fume in this material is chosen to be $14 \%$. it is a dosage optimized by experiments which are no longer presented in this paper.

\begin{tabular}{llll}
\multicolumn{5}{c}{ Table 4. Mixing proportion of pervious concrete } \\
\hline Specimens & CSP & ASP & BASP \\
\hline Mix proportion $\left(\mathrm{kg} \mathrm{m}^{3}\right)$ & & & \\
Cement & 300 & 300 & 300 \\
Water & 48 & 48 & 48 \\
Coarse aggregate & 1800 & $1800-1260$ & 1476 \\
Fine aggregate & 200 & 200 & $200-140$ \\
$\quad$ Silica fume & 42 & 42 & 42 \\
$\quad$ Latex (water) & $54(48)$ & $54(48)$ & $54(48)$ \\
Replacing ratio of rubber aggregate by volume $(\%)$ & \\
A & - & $0-30$ & 18 \\
B & - & 0 & $0-30$ \\
\hline
\end{tabular}

\section{III.Test method}

\section{a. Strengths}

$40 \times 40 \times 160 \mathrm{~mm} 3$ specimens for strength testing of pervious concrete [1] with different replacing value of the rubber aggregate of mineral aggregate were prepared, their proportions were listed in Table 5. The strengths were measured to study the influence of the rubber aggregate replacement ratio on the strengths of polymer and silica fume pervious concrete. Three specimens were tested for each data point.

\section{b. The porosity and permeability}

The strength of concrete is affected by the volume of its overall voids [12]. In the complex microstructure of concrete, the pores can be present from the nano-scale to the macroscale. The difficulty of accurately testing the total porosity of pervious concrete arises from its unique microstructure. Compared with the pores within cement paste, the interconnected voids between the coarse aggregate are larger by several millimeters. Although it is well known that the method of mercury intrusion porosimetry (MIP) is effective for observing the pore configuration in normal concrete, the large amount of connected voids within the pervious concrete will cause dripping and leakage of mercury if pressure is applied. Thus, the method of MIP is not feasible for pervious concrete. The vacuum sealing apparatus is more appropriate to test a relatively accurate porosity of pervious concrete in laboratory research [13]. However, in practice, setting up such a delicate apparatus is challenging for concrete manufacturers and a simpler method is preferred. In the literature, Kearsley and Wainwright [14] have successfully used the Hoff equation [15] to estimate the total porosity of foam concrete. Similarly, Zheng [16] has presented an equation to estimate the total 
porosity of pervious concrete, which was analogous to the Hoff equation, but incorporated the aggregate proportions for pervious concrete. This is shown in the following equation:

$$
\rho_{t=}\left(\frac{100+P_{c}+0.25 P_{c}}{\frac{100}{\rho}+\frac{P_{c}}{\rho_{c}}+\left(0.25 P_{c} \times 0.75\right)}\right) \times \rho_{w}
$$

Where $\rho_{t}$ is theoretical density, $P_{c}$ is the cement to aggregate ratio by weight, $\rho_{c}$ is the specific gravity of cement, $\rho_{w}$ is the unit weight of water and $\rho$ is the aggregate apparent density. It can be seen that this equation was derived by understanding the cement hydration water to cement by weight, so the non-evaporable water mass is 0.25 times the anhydrous cement mass $P_{c}$; and the volume of this water reduces to approximately 0.75 of the original volume after chemically hydrating the cement [17]. Thus, the theoretical and effective porosity of the pervious concrete is calculated with the following equations:

$$
\begin{aligned}
& n_{o}=\left(1-\frac{\rho_{s}}{\rho_{t}}\right) \times 100 \\
& n_{e}=\left(1-\frac{m_{2}-m_{1}}{v \cdot \rho_{w}}\right) \times 100
\end{aligned}
$$

Where $n_{o}$ is the theoretical porosity of the pervious concrete, $n_{e}$ is the effective porosity of the pervious concrete, $\rho_{s}$ is the bulk density of the concrete, $\rho_{t}$ is the theoretical density of the concrete, $m_{1}$ is the weight of the specimen in the water after immersed in the water for $24 \mathrm{~h}, m_{2}$ is the weight of the specimen get out from the water and be dried at a temperature of $60{ }^{\circ} \mathrm{C}$ for $24 \mathrm{~h}, v$ is the volume of the specimen, $\rho_{w}$ is the density of the water.

The permeability of the pervious concrete is measured with equipment whose schematic is illustrated in Fig. 3. The permeability coefficient of the concrete is calculated with Darcy Law as the following equation:

$$
K_{T}=\left(\frac{Q . L}{A . \Delta . t}\right)
$$

Where $\mathrm{KT}$ is the permeability coefficient at water temperature $\mathrm{T}^{\circ} \mathrm{C}$ in $\mathrm{cm} / \mathrm{s}$, Q is the permeating water quantity in $\mathrm{cm} 3, \mathrm{~L}$ is the vertical distance of the measuring points of piezometric tubes in $\mathrm{cm}$, and the $\Delta \mathrm{h}$ is the meaning head pressure in $\mathrm{cm}, \mathrm{t}$ is the permeating time in second and $\mathrm{A}$ is the cross area of the specimen in $\mathrm{cm}^{2}$.

\section{Result and discussion}

\section{A. Strengths}

The compressive and flexural strength curves of different polymer and silica fume rubber aggregates pervious concrete with different rubber aggregates replacing value are illustrated in Fig. $4 \mathrm{a}$ and $4 \mathrm{~b}$ respectively. With the increase of replacing value, the compressive and the flexural strength of the pervious concrete reduce at first, but then increase and reach their maximum values respectively. Then compressive and flexural strength reduce again. This phenomenon shows that there is an optimum replacing volume ratio of rubber aggregate to the mineral in the polymer and silica fume pervious concrete in both of the ASP and BASP series of tests. When the replacing value is lower than the optimum level, the rubber aggregates cannot distribute uniformly the concrete, the strength of concrete reduce because the rubber aggregates with low elasticity modulus become some weak points so stress concentration occurs around the rubber particles [18].

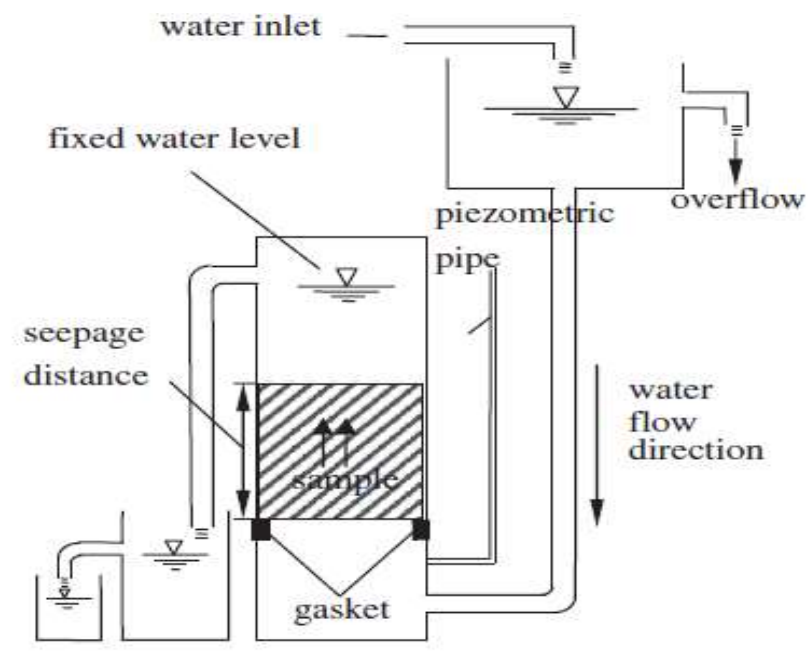

Figure 3. Diagrammatic representation of the process of the measurement of the permeability of the concrete and equipment

When the rubber aggregate content is high enough to distribute evenly throughout the material matrix, it can absorb the load energy uniformly [19], which leads to the increase of the concrete strength. When the replacing value is higher than the optimum value, the soft rubber aggregates make the framework of pervious concrete weaker and consequently the strength of concrete reduces again. From Fig. 4, it is clear that the optimum replacing value of A rubber aggregate is $18 \%$, and the optimum replacing value of $\mathrm{B}$ rubber aggregates is $14 \%$.

Comparing with CSP-0 (a polymer and silica fume pervious concrete without any rubber aggregate), the flexural strength of ASP-18 (polymer and silica fume-rubber aggregate pervious concrete with rubber aggregate) increases by $31 \%$ and its compressive strength increases just by $18 \%$. As per concluded by previous researchers, the strength of compacting concrete reduces because of the adding of rubber aggregate [3, 20-22] but both the flexural and compressive strength increase in case of adding rubber aggregate [1]. It is obvious from this research that by adding the silica fume to the modified rubber aggregate pervious concrete, both the flexural and compressive strength increase more that those without silica fume.

The increase of flexural strength is $1 \%$ and compressive strength is $6 \%$ more than this modified concrete without silica fume. Generally, the flexural strengths of the pavement materials are much more relevant to the performance of the pavement than their compressive strengths. It indicates that rubber aggregates improve the performance of pervious concrete as a pavement friction course.

BASP-14 has been prepared with the replacement of the fine aggregates in ASP-18 with B rubber aggregates. The flexural strength and compressive strength of BASP-14 
increase by $6 \%$ and $8 \%$ respectively compared to ASP-18. Because the small sized $\mathrm{B}$ rubber aggregates together with silica fume fill gaps among the coarse aggregates, and they distribute in the pervious concrete much more uneven than the A rubber aggregate, so the strengths of this series of pervious concretes increase comparing with ASP-18.

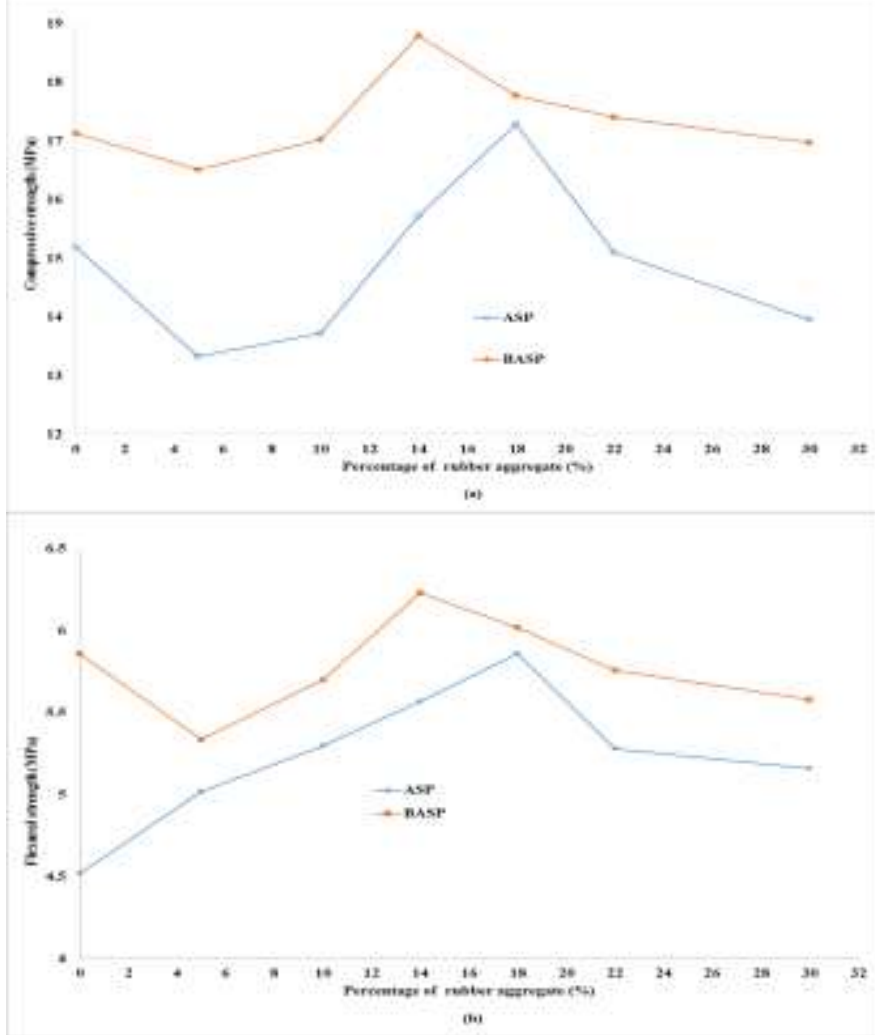

Figure 4. The strength of the concrete (a) Compressive strength (b) Flextural stress

\section{B. The porosity and permeability of the materials}

A coarse granular skeleton that develops stone-on-stone contacts and high connected air voids (AV) content is ideal for pavement concrete. This aggregate structure provides a higher degree of friction as well as permeability to the surface of the pavement. Stone-on-stone contact of the coarse aggregate fraction is required to provide mixture resistance to permanent deformation and disintegration, while the fine aggregate fraction fills the AV structure formed by the coarse aggregate in a compacted mixture [11]. The structure of connected AV provides drainability and reduces the water damage of pavement; it is known that an air viscous flow through microscopic channels of the pervious materials is a cause of sound energy damping [26], so this material can also have an advantage of sound reduction when it is used as thin surface pavement courses. Standard Practice for Open-Graded Friction Course (OGFC) Mix Design1 (ASTM Designation: D7064/D7064 M - 08E1) required the porosity of OGFC not less than $18 \%$ and permeability higher than $100 \mathrm{~m} /$ day $(0.116$ $\mathrm{m} / \mathrm{s})$.

From Table 5, it can be seen that the porosity of this concrete is above the standard of OGFC means $18 \%$, the permeability of the pavement wearing materials is much higher than $0.5 \mathrm{~cm} / \mathrm{s}$ and can meet the standard of the OGFC also.

Table 5. The test results of porosity and permeability

\begin{tabular}{llll}
\hline Index & CSP & ASP-18 & BASP-14 \\
\hline $\begin{array}{l}\text { Effective } \\
\text { porosity(\%) }\end{array}$ & 18.8 & 18.0 & 18.4 \\
$\begin{array}{l}\text { Whole porosity (\%) } \\
\text { Permeability (cm/s) }\end{array}$ & 19.9 & 18.6 & 19.5 \\
\hline
\end{tabular}

\section{v. Conclusion}

Based on the experimental results, it was concluded that the optimum replacing value of $\mathrm{A}$ and $\mathrm{B}$ rubber aggregates are $18 \%$ and $14 \%$, respectively which lead to the maximum flexural strength and compressive strength. The flexural strength is increased more obviously than the compressive by the replacement of mineral aggregate with rubber aggregate.

The porosity of the friction course is above $18 \%$ and the permeability is higher than $0.5 \mathrm{~cm} / \mathrm{s}$ which are both above the standard of the ASTM OGFC. Consequently, this pervious concrete can be used as friction course material of pavement. The interleaving of polymer film in the cement hydration products, the rubber aggregate distributing throughout the volume of paste and the dense rubber-cement paste interfacial transition zone give the polymer and silica fume-rubber aggregate pervious concrete ductility, which leads to higher performance than the ordinary polymer pervious concrete as a pavement friction course material.

\section{References}

1. Shen, W., et al., Investigation on polymer-rubber aggregate modified porous concrete. Construction and Building Materials, 2013. 38: p. 667-674.

2. Benaicha, M., et al., Influence of silica fume and viscosity modifying agent on the mechanical and rheological behavior of self compacting concrete. Construction and Building Materials, 2015. 84: p. 103-110.

3. Pelisser, F., et al., Concrete made with recycled tire rubber: effect of alkaline activation and silica fume addition. Journal of Cleaner Production, 2011. 19(6): p. 757-763.

4. Güneyisi, E., et al., Experimental investigation on durability performance of rubberized concrete. Advances in concrete construction, 2014. 2(3): p. 187-201.

5. Emiroglu, M., S. Yildiz, and M.H. Kelestemur, A study on dynamic modulus of self-consolidating rubberized concrete. Computers and Concrete, 2015. 15(5): p. 795-805.

6. Abrham, K.S., THE USE OF RECYCLED RUBBER TIRES AS A PARTIAL REPLACEMENT FOR COARSE AGGREGATES IN CONCRETE CONSTRUCTION. 2009.

7. Muhammad, B., et al., Influence of non-hydrocarbon substances on the compressive strength of natural rubber latex-modified concrete. Construction and Building Materials, 2012. 27(1): p. 241-246.

8. Paje, S., et al., Acoustic field evaluation of asphalt mixtures with crumb rubber. Applied Acoustics, 2010. 71(6): p. 578582.

9. Khatib, Z.K. and F.M. Bayomy, Rubberized Portland 
cement concrete. Journal of materials in civil engineering, 1999. 11(3): p. 206-213.

10. Ashour, A.F. and I.F. Kara, Size effect on shear strength of FRP reinforced concrete beams. Composites Part B: Engineering, 2014. 60: p. 612-620.

11. Gerharz, B., Pavements on the base of polymermodified drainage concrete. Colloids and Surfaces A: Physicochemical and engineering aspects, 1999. 152(1): $\mathrm{p}$. 205-209.

12. Mui, E.L., W. Cheung, and G. McKay, Tyre char preparation from waste tyre rubber for dye removal from effluents. Journal of hazardous materials, 2010. 175(1): p. 151-158.

13. Huang, B., et al., Laboratory evaluation of permeability and strength of polymer-modified pervious concrete. Construction and Building Materials, 2010. 24(5): p. 818-823.

14. Kearsley, E. and P. Wainwright, The effect of porosity on the strength of foamed concrete. Cement and concrete research, 2002. 32(2): p. 233-239.

15. Hoff, G.C., Porosity-strength considerations for cellular concrete. Cement and Concrete Research, 1972. 2(1): p. 91-100.

16. ZHENG, M.-1., S.-f. CHEN, and B.-g. WANG, Physical and mechanical performance of porous concrete for drainage base [J]. Journal of Xi'an University of Science and Technology, 2007. 4: p. 017.

17. Lian, C., Y. Zhuge, and S. Beecham, The relationship between porosity and strength for porous concrete. Construction and Building Materials, 2011. 25(11): p. 42944298.

18. Mindess, S., F. Young, and D. Darwin, Concrete 2nd Editio. 2003, Upper Saddle River, NJ: Pearson Education, Inc.

19. Benazzouk, A., et al., Effect of rubber aggregates on the physico-mechanical behaviour of cement-rubber composites-influence of the alveolar texture of rubber aggregates. Cement and Concrete Composites, 2003. 25(7): p. 711-720.

20. Topcu, I.B., The properties of rubberized concretes. Cement and concrete research, 1995. 25(2): p. 304-310.

21. Toutanji, H.A., The use of rubber tire particles in concrete to replace mineral aggregates. Cement and Concrete Composites, 1996. 18(2): p. 135-139.

22. Alvarez, A.E., A.E. Martin, and C. Estakhri, A review of mix design and evaluation research for permeable friction course mixtures. Construction and Building Materials, 2011. 25(3): p. 1159-1166.

23. Zhang, X., Z. Jiang, and B. Chen, Study on impactproof and abrasion-proof concrete in runway. Journal of Nanjing University of Aeronautics \& Astronautics, 2002. 34(2): p. 114-120.

24. Turatsinze, A., S. Bonnet, and J.-L. Granju, Mechanical characterisation of cement-based mortar incorporating rubber aggregates from recycled worn tyres. Building and environment, 2005. 40(2): p. 221-226.

25. Hernández-Olivares, F., et al., Fatigue behaviour of recycled tyre rubber-filled concrete and its implications in the design of rigid pavements. Construction and building materials, 2007. 21(10): p. 1918-1927.

26. Voronina, N., An empirical model for rigid frame porous materials with high porosity. Applied Acoustics, 1997. 51(2): p. 181-198. 